\title{
EFFECTS OF RECOVERY DURING INTERVAL TRAINING ON CARDIOVASCULAR FUNCTION
}

\author{
R. T. DAVIS, MA \\ Appalachian State University, Boone, North Carolina \\ J. L. MAYHEW, MSc \\ Department of Physical Education, University of Illinois, Champaign, Illinois
}

Since its inception in the late 1930 's, interval training has become the most widely accepted method of endurance training (Down, 1964). By manipulating the four basic elements of interval training (distance, time, repetitions, and recovery) the desired stimulus on organic function can be attained. Recent work has shown that not the least important of these is the recovery phase (Bonen, 1970).

Controversy appears evident concerning the manner of determining recovery during interval training. Several sources (Nett, 1964; Doherty, 1967; Jensen and Fisher, 1972) advocate a strict time recovery, while others (Caufield, 1965; McArdle and Patti, 1967; Mathews and Fox, 1971) prefer allowing the heart rate to return to approximately 120 beats/minute before beginning the next repetition. The use of 120 beats/minute as the criterion of physiological readiness for the next effort phase is based on the work of Gerschler (Sprecher, 1964). Apparently below that critical heart rate the peripherial capillaries begin to constrict and the expansion effect on the heart is lessened (Nett, 1964). Some authorities (Down, 1966; Wilt, 1968) claim that such a phenomenon occurs after two-to-three minutes of recovery, hence time is at least as important as heart rate in setting recovery duration.

Wilt (1968) and other coaches make the distinction between "fast" and "slow" interval training. Their contention is that fast repetitions more significantly affect muscle metabolism, while slow repetitions benefit the cardiovascular system to a greater extent. However, Yakovlev et al. (1961) found that repetitive, short sprints with brief recovery intervals produced substantial gains in aerobic function. Webb (1967) demonstrated that a short-distance interval training programme $(50-200 \mathrm{~m})$ produced a significant improvement in the Harvard Step Test Recovery Index by the fifth week, while long- $(600-1200 \mathrm{~m})$ and mixed-distance $(50-1200 \mathrm{~m})$ interval programmes required eight weeks to achieve that end.

Following its development (Johnson, Brouha, and Darling, 1942), the Harvard Step Test (HST) has been widely used to assess cardiovascular response to heavy stress. The standard format of the test has subjects step for five minutes (or until exhausted from fatigue) at $\mathbf{3 0}$ steps/minute on a $50 \mathrm{~cm}$. bench (Johnson, Brouha, and
Darling 1942). Recovery pulse counts are standardly taken at 1-1.5, 2-2.5, and 3-3.5 minutes after exercise, although the original article indicated the last count was taken at 4-4.5 minutes following stepping. The Recovery or Fitness Index is calculated by (Johnson, Brouha, and Darling, 1942):

$$
\text { R.I. }=\frac{\text { Duration of exercise }(\text { secs) } \times 100}{2 \times \text { Sum of pulse counts for 1-1.5, 2-2.5, 3-3.5 }}
$$

A score of 55 or below indicates poor cóndition, 65-79 average fitness, and above 90 is excellent (Brouha, 1943).

Gallagher and Brouha (1944) contended that the test was not a measure of skill but of the quality of the cardiovascular response to strenuous exercise. With an energy cost and efficiency rating of $21.250 \mathrm{cal} / \mathrm{kg} / \mathrm{min}$ and $17.5-21.9 \%$, respectively, (Rovelli and Aghemo, 1963; Ricci et al., 1966), and with the limited muscle mass involved, the HST may be considered "heavy" work which cannot be prolonged beyond five minutes in the average individual (Rovelli and Aghemo, 1963). Prior

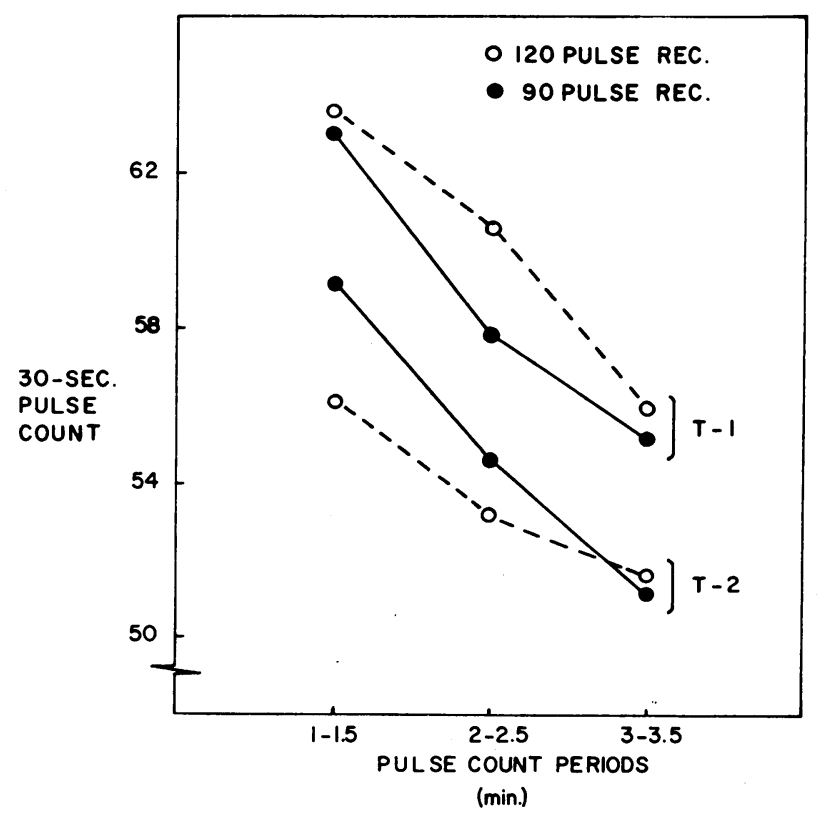

Figure 1. Individual pulse counts at $T-1$ and $T-2$. 
to training from $3-48 \%$ of the individuals tested can be expected not to complete five minutes of stepping (Johnson, Brouha, and Gallagher, 1943; Keen and Sloan, 1958), although this may reflect motivation levels and discomfort tolerance rather than cardiovascular response (Ricci et al., 1966; Wilmore, 1968).

Post-exercise heart rate has been shown to be sensitive to training programmes (Montoye, 1953). Michael and Gallon (1959) observed that basketball players had made a significant improvement (.05 level) in the HST by the third week of training; they showed further improvement ( 0.1 level) by the third week.

Therefore, the purpose of this study was to assess the effect of two forms of recovery during fast interval training on the cardiovascular system as determined by the Harvard Step Test.

\section{Procedure}

Eighteen male volunteers were subjects for this study. Training groups were equated initially on the basis of HST scores. Group physical characteristics are shown in Table I.

All subjects trained using sprints of $50-200 \mathrm{~m}$. One group $(N=9)$ recovered to approximately 120 beats/minute heart rate between sprints. The other group $(N=9)$ rested 90 seconds between sprints. Training duration was $\mathbf{3 0}$ minutes per day, four days each week for five weeks. All subjects employed the same sprint runs on a given day, although the total distance covered may not have been equal due to the difference in recovery. In addition, individual variation in total distance within the pulse recovery group was evident.

The HST was administered according to standard procedures (Johnson, Brouha, and Darling, 1942). If a subject felt behind the stepping pace for a duration of 10-15 seconds, he was halted and the recovery phase begun (Brouha, Graybiel, and Heath, 1943). Pulse recovery counts were recorded at the radial artery by one of the investigators (RTD).

\section{Results and Discussion}

The correlations between HST and height $(r=.430)$ and HST and weight $(r=-.013)$ were not significant and suggested that the scores were not affected by either measure. This agreed with the contentions of Montoye (1953), Keen and Sloan (1958), and Ishiko (1967). Therefore, the HST appeared to be independent of anthropometric factors in assessment of cardiovascular function.

Following five weeks of "fast" interval training both groups had made highly significant improvements in Recovery Index (Table II). Webb (1967) also noted that a short-distance interval training group made more rapid improvement in Recovery Index than either long-or mixed-distance interval groups, although this is contridictory to the findings of Karlsson, Asstrand, and Ekblom (1967).

The great percentage improvement shown here (Table II) agreed with the observations of Fletcher (1960). Other investigators (Brouha, Graybiel, and Heath, 1943; Gallagher and Brouha, 1943) have noted that subjects with the lowest initial scores made the greatest improvement due to training. However, mean scores as low as those reported here could not be found in the literature, although Fletcher (1960) did report brief stepping periods for older subjects. This may reflect lack of motivation or low tolerance on the part of our subjects for the stress of exercise (Ricci et al., 1966; Wilmore, 1968), although if subjects cease stepping for reasons other than cardio-respiratory inadequacy, the recovery heart rates would have been lower and Recovery Index higher. Therefore, it may be assumed that the subjects were initially, through no selection process, extremely unfit.

The fact that so great an improvement in cardiovascular function was shown (Table II) may also reflect the intensity of the training stimulus (Faria, 1970). Other researchers have demonstrated that more intense training, as reflected by heart rate, produced the greatest endurance gains (Sharkey and Holleman, 1967; Sharkey, 1970). Shephard (1968) indicated that response to training depends on intensity in conjunction with initial level of fitness.

High-speed, repetitive running has been hypothesized to develop muscle metabolic processes rather than cardiovascular condition (Nett, 1964). Our findings do not confirm this opinion. Rather, these data coincide with conclusions of Åstrand et al. (1960), Fox, Robinson, and Wiegman (1969), and Margaria et al. (1969) that when high intensity work phases of short duration $(10-30$ secs) are punctuated by brief rest periods, the work is performed predominantly aerobically with considerable stimulus to the cardiovascular system.

The fact that there was no significant difference between the two groups in Recovery Index following training may indicate that the pulse rate was returning to 120 beats/minute within 90 seconds following each run (Figure 1). Although the duration of the pulse recovery group interval was not recorded, it may be that, following initial adjustment to exercise stress, it was equal to or less than $\mathbf{9 0}$ seconds.

The question of the best method of training for 
optimum development of the cardiovascular system remains a formidable one. In addition, improvements in performance without corresponding gains in maximum aerobic capacity over a period of training (Dainty, Kollias, and Nelson, 1972) raise the question whether certain physiological parameters can be increased

Table I

Group physical characteristics

\begin{tabular}{|c|c|c|c|c|c|c|c|c|c|c|c|}
\hline Group & $\begin{array}{l}\text { Age } \\
\text { (yrs) }\end{array}$ & $\begin{array}{l}\text { Height } \\
\text { (cm) }\end{array}$ & $\begin{array}{l}\text { Weight } \\
\text { (kg) }\end{array}$ & $\begin{array}{l}\text { BSA } \\
\left(m^{2}\right)\end{array}$ & Group & $\begin{array}{l}T-1 \\
\text { Mean S.D. }\end{array}$ & $\begin{array}{l}T-2 \\
\text { Mean }\end{array}$ & S.D. & Mean & $\begin{array}{l}\text { \% } \\
\text { Change }\end{array}$ & $\begin{array}{l}t \\
\text { ratio }\end{array}$ \\
\hline 120 Pulse Rec. & $\begin{array}{l}19.26 \\
\pm 0.86\end{array}$ & $\begin{array}{l}179.2 \\
\pm 7.1\end{array}$ & $\begin{array}{l}68.90 \\
\pm 7.08\end{array}$ & $\begin{array}{l}1.86 \\
\pm 0.12\end{array}$ & $\begin{array}{l}120 \text { Pulse Rec. } \\
\text { 90-Sec. Rec. }\end{array}$ & $\begin{array}{ll}26.44 & 5.56 \\
25.55 & 5.62\end{array}$ & $\begin{array}{l}94.22 \\
91.22\end{array}$ & $\begin{array}{l}10.12 \\
3.99\end{array}$ & $\begin{array}{l}+67.78 \\
+65.67\end{array}$ & $\begin{array}{ll}8 & 256.4 \\
7 & 257.0\end{array}$ & $\begin{array}{l}21.6^{*} \\
39.7^{*}\end{array}$ \\
\hline 90-Sec. Rec. & $\begin{array}{l}19.56 \\
\pm 1.15\end{array}$ & $\begin{array}{l}175.6 \\
\pm 8.0\end{array}$ & $\begin{array}{l}65.93 \\
\pm 12.44\end{array}$ & $\begin{array}{l}1.80 \\
\pm 0.19\end{array}$ & ifirant & 01 level. & & & & & \\
\hline
\end{tabular}

\section{REFERENCES}

ÅSTRAND, I., et al. "Myohemoglobin as an Oxygen-Store in Man." Acta Physiologica Scandinavica, 48: 454-460, 1960.

BONEN, A. "Cardio-Respiratory Effects of Interval Training with Varied Rest." M. S. thesis. University of Illinois, Urbana, III., 1970.

BROUHA, L. "The Step Test: A Simple Method of Measuring Physical Fitness for Muscular Work in Young Men." Research Quarterly, 14: 31-36, 1943.

BROUHA, L., A. GRAYBIEL, and C. W. HEATH. "The Step Test: A Simple Method of Measuring Physical Fitness for Hard Muscular Work in Adult Men." Revue Canadienne de Biologie, 2: 86-91, 1943.

CAUFIELD, H. D. “Pulse Swimming." Athletic Journal, 46(4): 14, 1965.

DAINTY, D. A., J. KOLLIAS, and R. C. NELSON. "A Longitudinal Investigation of the Phsyiological and Biochemical Characteristics of Experienced Runners." Paper presented at Conference of American College of Sports Medicine, Philadelphia, Pa., 1972.

DOHERTY, J. K. “A Training Programme for Endurance Running." Scholastic Coach, 36(6): 17-18, 57, 1967.

DOWN, M. G. "An Appraisal of Interval Training." Ibid 25: 791-795, 1966.

DOWN, M. G. "An Appraisal of Interval Training." 25: 791-795, 1966.

FARIA, I. E. "Cardiovascular Response to Exercise as Influenced by Training of Various Intensities." Research Quarterly, 41: 44-50, 1970.

FLeTCHER, J. G. “Maximal Work Production in Man." Journal of Applied Physiology, 15: 764-767, 1960.

FOX, E. L., S. ROBINSON, and D. L. WIEGMAN. “Metabolic Energy Sources during Continuous and Interval Running." Journal of Applied Physiology, 27: 174-178, 1969.

GALLAGHER, J. R., and L. BROUHA. "The Evaluation of Athletic Programmes by Means of Fitness Tests." Yale Journal of Biology and Medicine, 15: 671-677, 1943. 
GALLAGHER, J. R., and L. BROUHA. "Physical Fitness: Its Evaluation and Significance." Joumal of the American Medical Association, 125: 834-838, 1944.

HENRY, F. M., and W. G. BERG. "Physiological and Performance Changes in Athletic Conditioning." Journal of Applied Physiology, 3: 103-111, 1950.

ISHIKO, T. "Aerobic Capacity and External Criteria of Performance." Canadian Medical Association Journal, 96: 746-749, 1967.

JENSEN, C. R., and A. G. FISHER. Scientific Bases of Athletic Conditioning. Philadelphia, Pa.: Lea and Febiger, 1972.

JOHNSON, R. E., L. BROUHA, and R. C. DARLING. "A Test of Physical Fitness for Strenuous Exertion." Revue Canadienne de Biologie, 1: 491-503, 1942.

JOHNSON, T. L., L. BROUHA, and J. R. GALLAGHER. "The Use of the Step Test in the Evaluation of the Fitness of Adolescents." Yale Journal of Biology and Medicine, 15: 781-785, 1943.

KARLSSON, J., P. O. ÅTTRAND, and B. EKBLOM. "Training of the Oxygen Transport System in Man." Journal of Applied Physiology, 22: 1061-1065, 1967.

KEEN, E. N., and A. W. SLOAN. "Observations on the Harvard Step Test." Journal of Applied Physiology, 13: 241-243, 1958.

MARGARIA, R., et al. "Energy Utilization in Intermittent Exercise of Supramaximal Intensity." Journal of Applied Physiology, 26: 752-756, 1969.

MATHEWS, D. K., and E. L. FOX. The Physiological Basis of Physical Education and Athletics. Philadelphia, Pa.: W. B. Saunders, 1971.

MCARDLE, W. D., and A. V. PATTI. "Pulse Rate: A Scientific Approach to Training." Scholastic Coach, 37(2): 29, 76-78, 1967.

MICHAEL, E. D., and A. GALLON. "Periodic Changes in the Circulation during Athletic Training as Reflected by a Step Test." Research Quarterly, 30: 303-311, 1959.

MONTOYE, H. J. "The 'Harvard Step Test' and Work Capacity." Revue Canadienne de Biologie, 11: 491-499, 1953.

NETT, T. "Examination of Interval Training." Cited in F. Wilt (ed.), Run, Run, Run. Los Altos, Calif.: Track and Field News, 1964. Pp. 197-204.

RICCI, B., et al. "Energy Cost and Efficiency of Harvard Step-Test Performance." Internationale Zeitschrift fur Angewandte Physiologie, 22: 125-130, 1966.

ROVELLI, E., and P. AGHEMO. "Physiological Characteristics of the 'Step' Exercise." Internationale Zeitschrift fur Angewandte Physiologie, 20: 190-194, 1963.

SHEPHARD, R. J. "Intensity, Duration, and Frequency of Exercise as Determinants of the Response to a Training Regime." Internationale Zeitschrift fur Angewandte Physiologie, 26: 272-278, 1968.

SHARKEY, B. J. "Intensity and Duration of Training and the Development of Cardio-respiratory Endurance." Medicine and Science in Sports, 2: 197-202, 1970.

SHARKEY, B. J., and J. P. HOLLEMAN. "Cardio-respiratory Adaptations to Training at Specified Intensities." Research Quarterly, 38: 698-704, 1967.

SPRECHER, P. "Visit with Dr. Woldernar Gerschler." Cited in F. Wilt (ed.), Run, Run, Run. Los Altos, Calif.: Track and Field News, 1964. Pp. 150-152. 
WEBB, W. M. "Three Interval Training Programmes and Their Effects on Selected Physiological Variables." Ph.D. thesis. Ohio State University, Columbus, Ohio, 1967.

WILMORE, J. H. "Influence of Motivation on Physical Work Capacity and Performance." Journal of Applied Physiology, 24: 459-463, 1968.

WILT, F. "Training for Competitive Running." Cited in H. B. Falls (ed.), Exercise Physiology. New York, N.Y.: Academic Press, 1968. Pp. 395-414.

UNESCO, INTERNATIONAL COUNCIL OF SPORT AND PHYSICAL EDUCATION

PHILIP NOEL-BAKER RESEARCH PRIZE, 1974, TO DR. J. G. P. WILLIAMS

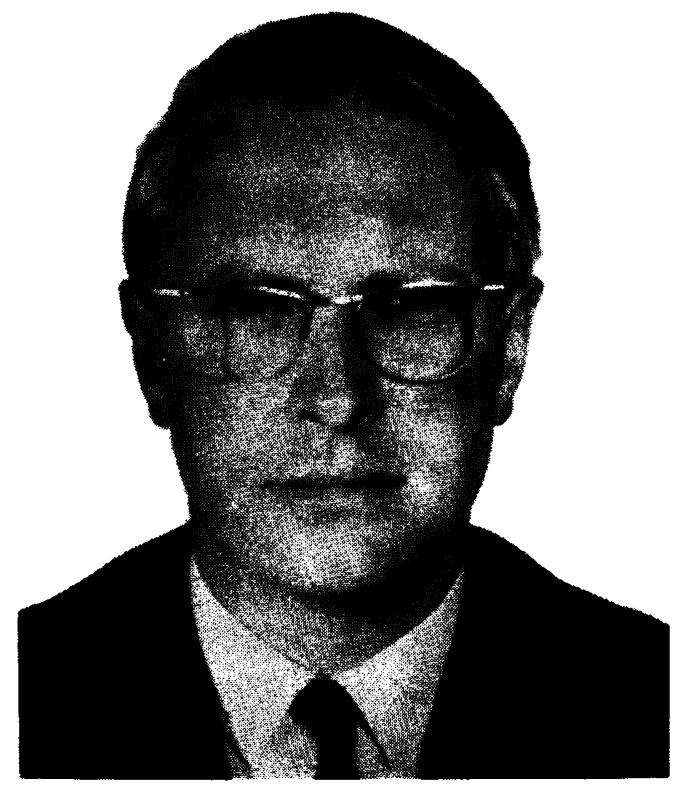

UNESCO's International Council of Sport and Physical Education have announced the award of the annual Philip Noel-Baker Research Prize, 1974 to Dr. John G. P. Williams. This award is made "in appreciation of Dr. Williams' sustained contributions in the field of sports medicine as well as his active cooperation in all matters pertaining to scientific research relating to sport and physical education". The Executive Committee of B.A.S.M. is proud to announce this honouring of its former Secretary, who is presently Medical Director of Farnham Park Rehabilitation Centre and Secretary General of the Federation Internationale de Medecine Sportive.

Dr. Williams has been active in sports medicine in Britain and abroad since 1960, has been a pioneer in running sports clinics and has published widely on sports medical topics, including the standard text "Sports Medicine". He has lectured widely at home and abroad. 